\title{
The study of bureaucracy in the administrative organizations of Iran (The Case of personnel of govermental organizations in Ahwaz city)
}

\author{
A. H. Hosseinzade \\ Associate Proffesser of Shahid Chamran UNI of Ahwaz \\ S. Allameh \\ M.A of Sociology of Shahid Chamran UNI of Ahwaz
}

\begin{abstract}
This study represents an attempt to examine bureaucracy in the administrative organizations of Iran as a developing country. Therefore, this study aims to study how the bureaucratic structure of organization and its dimensions are in the administrative organizations of Iran. This study was carried out through the survey method. The data research have been collected by survey from a sample 400 person taken from the staffs population of $\mathbf{3 0}$ governmental organizations of Ahwaz through stratified cluster sampling. The results showed that bureaucracy in the administrative organizations of Iran is multidimensional and it can't be considered as an unitary concept. Also, six dimensions of bureaucratic structure form two high-order factors that are inversely correlated together. First factor is control including Hierarchy of authority, rule observation and formality in relations(impersonality). Second factor is expertise including job codification, technical competence and division of labor. Also, it was seen differences between western bureaucratic models and bureaucracy in the administrative organizations of Iran as a developing country.
\end{abstract}

Keywords: Bureaucracy, Organizational structure, Control, Expertise, Administrative organizations of Iran.

\section{INTRODUCTION}

In the present times, it's impossible to lead a social life without organizations; organizations that are formed based on social needs and play a significant role in operation of society and accomplishment of the development plans. Bureaucracy is one of the forms of organizing human activities to answer a certain need. Max Weber is one of the first theoreticians of organizational structure, who has emphasized on dominance of bureaucracy in comparison to other forms of organization. He suggested that the main reason for the advantage of bureaucratic organization has always been its purely technical superiority over any form of organization(Greth \& Mills 1946:214). Nowadays though the idea that bureaucracy is the only way to operate big organizations gradually becomes obsolete, but still lots of bureaucracies exist in the world and have dominance over all human activities, from production and distribution to guidance and transportation systems and urban and rural issues even birth control regulations (Giddenz, 2003).

The aim of present article is to study bureaucracy and its dimensions in Iran's bureaucratic organizations. As most of developing countries, Iran has adopted its bureaucratic model from west. But not much is known about bureaucratic organizations of the developing countries, including Iran. Comparing to the bureaucratic organizations of the western countries, there have been few studies on bureaucratic organizations of the third world countries, and most of the studies have been carried out by western researchers and based on western organizations. 
However, it is said that the western bureaucratic models are different from those of the developing countries' (kanango, 1992). Hence we as a developing country must investigate that how is bureaucracy in Iran's organizations and does the bureaucratic structure of organizations in this country have any differences to the models of western organizations? In this regards, this article is an exploratory study to gain more knowledge on bureaucratic structures and its dimensions in governmental organizations of Iran, as a developing country. Berger (1975) believed that using the existing studies in west as guidance for studying the bureaucracy in other cultures will outline and show the limitations of these studies in reviewing the bureaucratic attitudes and behaviors in non-western and western societies. Therefore, studying the bureaucracies in developing countries, not only will show the bureaucratic structure in these countries, but also will help to show the differences between developing and western bureaucratic organizations and will generally add to our knowledge about these organizations .

Hence in order to undertake an exploratory study about bureaucracy and its aspects in Iran's administrative organizations as a developing country, this study will raise following question:

How dimensions of bureaucratic structure of administrative organizations in Iran are related?

To answer this question first the correlation matrix of dimensions of bureaucratic structure were reviewed and then for further and deeper investigations, we used the exploratory factor analysis. The theoretical basis of the present study is based on Max Weber's ideal theory of bureaucracy and conceptualization of Richard hall of his theory.

\section{THEORETICAL AND EXPERIMENTAL BACKGROUND}

Basis of the studies carried out on organizational structure is based on bureaucratic theory of Max Weber. He presented an ideal type of organizational structure called Bureaucracy. According to his theory, bureaucracy is defined as a form of administrative organization designed to reach efficiency through rationalization of organizational behaviors (Meyer, 1972). According to Weber's theory, Organizational tasks are distributed among the various positions as official duties. The positions or offices are organized into a hierarchical authority structure. A formally established system of rules and regulations govern official decisions and actions. Officials are expected to assume an impersonal orientation in their contacts with clients and with other officials (Blau \& Scott, 1962:32). Based on given characteristics by Weber, there is some puzzlement about conceptualization of bureaucracy in the literature of bureaucratic organizations. Blau and Scott (1962) and Blau and Marshal (1974) have named 5 main dimensions: Hierarchy of authority, division of labor (specialization), system of regulations (formality), impersonality (not having personal dependency), and recruitment and promotion based on technical competence. Following reviewing some studies, Hall (1963) concluded that there's an important agreement on main factors (Anderson, 1973). He(1963) identified 6 dimensions for bureaucracy based on Weber's theory: Hierarchy of authority, division of labor, rules and regulations, procedural specification, impersonality and technical competence. The present study also considers hierarchy of authority, division of labor, job codification and rules observation $^{1}$, impersonality and technical competence as the bureaucratic dimensions of an organization. These dimensions - which describe organizations as physical characteristics and personality of individuals- give us a basis by which we're able to measure and compare organizations.

1- Dimentions of job codification is similar to the procedural specification and dimension of rule observation is similar to the rules and regulations. 
One of the most important issues in the bureaucratic literature is to define a Unitary or dimensional approach for assessing the bureaucratic structure of an organization. The primary works (Moeller, 1962; udy, 1959; Berger, 1957) studied bureaucracy with a unitary approach. According to this approach, an organization is, or is not bureaucratic. Researchers who applied this approach believed that in order to define an organization as bureaucratic, we should be able to witness high degrees of all the dimensions of bureaucracy in that organization. But later, this approach was seriously questioned. It was said that all the dimensions of bureaucracy might not be present in an organization at the same time. Organizations are different in their degree of bureaucratization. Some dimensions can be stronger than others. Dimensions can be independent of each other. They can change independently from each other. Bureaucratic dimensions can create different configurations of bureaucracies (Hall, 1963; Bonjean \&Grimes, 1971; Yucel, 1999). Anderson $(1973,1971)$ also discussed that sum of the scale scores is not acceptable for reaching a total grade for bureaucracy, because it might average out the important differences arising from one scale to another. Hence in 1960 decade, the unitary approach which described bureaucracy as a single dimension and as an absentpresent dichotomy was gradually dismissed.

But in the dimensional approach, it's discussed that an organization can be bureaucratic in different ways. An organization can have high degrees of bureaucratization in some dimensions but not in some other dimensions. Bureaucratic dimensions can vary independent from each other. They does not necessarily converge together (Hall, 1963; Bonjean \& Grimes, 1971; Anderson, 1971; Yucel, 1999). Berger (1957) had also reported few convergent changes among bureaucratic dimensions. Hall and Title (1966) and Bonjean and Grimes $(1970,1971)$ believe that the technical competence dimension is different from other bureaucratic dimensions and it has negative correlation with them. In some other studies (Anderson, 1973, 1971; Punch, 1969; Esherwood \& Hoy, 1973; Yucel, 1999), researchers believe that division of labor and technical competence are two dimensions that are not convergent with the other bureaucratic dimensions.

They discuss that together, these two dimensions make the expertise which has a negative relation with control factor including hierarchy of authority, impersonality, rules and regulations (rules observation) and procedural specification (job codification). In fact, these studies recognized that 6 bureaucratic dimensions make two more general and specific factors that are negatively related to each other.

Esherwood \& Hoy (1973) presented a four-fold typology of bureaucratic structures, based on these two general factors -control and expertise-. They calculated the means of two factors for each organization. Then, they compared the means of each organization on the two factors to the grand means of all organizations on the two factors. 1) If an organization possesses a low degree of control and expertise compared to the grand means of all organizations on two factors, it's called «Chaotic». In chaotic organizations, ambiguity and conflict are evident. The dominant source of power is political connections. Decisions are made in an irrational way and there's no coordination of activities. These types of organizations are unstable and desire to move towards another model. 2) If an organization has a high degree of control and low degree of expertise compared to the grand means of all organizations on two factors, it's called «Authoritarian». In this model a bureaucratic authority is applied at the expense of technical considerations. Authority is centralized at the higher levels of hierarchy. Rules are enforced to assure compliance. Rules are enforced in an impersonal way. Those who are loyal to superiors are promoted or approved of. Obedience of the staff is most emphasized. Objectives are clear and known and decisions are overly rational.3) If an organization has a low degree of control and high degree of expertise compared to the grand means of all organizations on two factors, 
it's called «Collegial». In this model, decision-making is granted to the members of the organizations. Rules and regulations are considered as guidelines. People are trusted and goals are not important. 4) If an organization has a high degree of control and high degree of expertise compared to the grand means of all organizations on two factors, it's called «Weberian». In this model, bureaucratic and technical characteristics complete each other. This study also uses this four-fold typology as an analyzing tool to understand Iran's governmental organizations. The aim of using this typology was to define rather homogenous groups of employees on control and expertise factors which present us different types of organizational bureaucracies. Figure 1 shows two factors and 4 types of bureaucracies. Since in this study, the bureaucratic dimensions of organizational structure is the perception of employees from these regulations in the organization (refer to measurement section), it must be said that in fact this typology is a classification of perceptions of employees of bureaucracy of the organization.

Figure 1 The Classification of employees ' Perceptions of Bureaucracy(Cited by Yucel,1999)
\begin{tabular}{|c|c|c|}
\hline & Low expertise & High expertise \\
\hline High control & Authoritarian & Weberian \\
\hline Low control & Chaotic & Collegial \\
\hline
\end{tabular}

\section{METHODOLOGY}

This research was carried out through the survey method. The sample of this research includes 400 persons(390 useful individuals), that was determined from statistical population employing Krejcie and Morgan's table of determining sample size (1970). The sample members were drawn from all employees in 30 governmental organization, affiliated by the management and planning organization in Ahwaz, capital of Khuzestan, a Province in south west of Iran. Out of 11 manufacturing organizations, 2 organizations and from 19 socio-public organizations, 3 organizations were randomly selected. A classified cluster sampling method has been used to select the samples. Main instrument of data collection used in this study was questionnaire. The validity of the scales were attained through content validity procedure and the opinions of the judges. Reliability of the scales were calculated by Cronbach's Alpha. Also to test the scales, a pretest was done with 50 individuals from the statistical population.

\section{Measurement}

In the studies related to bureaucracy, two approaches are used to measure the bureaucratic dimensions. One alternative is the perceptions of organization participants of Bureaucratic charactristics of organizational structure. The other is the structural characteristics themselves. Hall $(1962,1963)$ believes that the first one is appropriate approach to measure Bureaucratic charactristics of organizational structure. Because the use of objective measures ignores intraorganizational variation which may be significant both horizontally and vertically. Hence in this study, scales are perceptions of people of bureaucratic dimensions of the organizational structure.

Hierarchy of Authority (HA): it means the freedom provided for the members of an organization to undertake their specific tasks without interference of higher level authorities (Aiken\&Hage, 1966,1967). In this study we have used Aiken and Hage's scale of hierarchy of authority(1966). Hierarchy of authority is one of the important dimensions of organizational centralization. This scale has 5 five-point Likert-type items and the answers consisted of "completely wrong", "Wrong", "Almost correct", "correct", and "completely correct". The Cronbach's alpha for this scale is $80 \%$. 
Rules observation(RO): rules observation reflects the degree to which employees are observed for rule violations(Aiken\&Hage, 1966;Hall, 1997). In this study we have used the scale developed by Aiken and Hage (1966). This scale has 7 five-point Likert-type items and the answers consisted of "completely wrong", "Wrong", "Almost correct", "correct", and "completely correct". The Cronbach's alpha for this scale is $60 \%$.

Job codification(JC): job codification reflects the degree to which job incumbents must consult rules in fulfilling professional responsibilities(Aiken\&Hage, 1966; Hall, 1997). In this study we have used the scale developed by Aiken and Hage (1966). This scale has 7 five-point Likerttype items and the answers consisted of "completely wrong", "Wrong", "Almost correct", "correct", and "completely correct". The Cronbach's alpha for this scale is 79\%.

Impersonality(FRM): It is the extend to which both organizational members and outsiders are treated without regard to individual qualities(Hall,1968). In this study we have used the scale advanced by Yucel (1999). This scale has two factors. (1) Formality is the degree to which interactions among people are formal and free from emotions. (2) Friendly climate is the degree to which relations in the organization are friendly and warm(Yucel,1999).

But Yucel suggests that the friendly climate factor is rather a non-structural and nonbureaucratic factor. Therefore, since the friendly climate factor is non-structural and nonbureaucratic factor, it was omitted from this study. Formality scale has 7 five-point Likert-type items and the answers consisted of "completely wrong", "Wrong", "Almost correct", "correct", and "completely correct". The Cronbach's alpha for this scale is 70\%.

Division of Labor (functional specialization)(DL): it is the extent to which work tasks are subdivided by functional specialization within the organization (Hall, 1968). Functional specialization means dividing labor to the specific, simple and repetitive responsibilities. (Robinson, 1997: 82\&262). In order to develop a scale for division of labor in this study, at first, some items collected from previous studies (i.e. Hall, 1961; punch, 1967; Mckay, 1964; refer to Yucel, 1999) were selected by the opinions of the judges; then after pretest studies, suitable items were chosen. This scale has 4 five-point Likert-type items and the answers consisted of "completely wrong", "Wrong", "Almost correct", "correct", and "completely correct". The Cronbach's alpha for this scale is $60 \%$.

Promotion based on technical competence(TC): It is the extent to which organizationally defined "universalistic"standards are utilized in the personnel selection and advancement (Hall, 1968). In this study, in order to develop a promotion scale based on technical competence, at first, some items collected from previous studies (i.e. Hall, 1961; punch, 1967; Mckay, 1964; refer to Yucel, 1999) were selected by the opinions of the judges; then after pretest studies, suitable items were chosen. This scale has 6 five-point Likert-type items and the answers consisted of "completely wrong", "Wrong", "Almost correct", "correct", and "completely correct". The Cronbach's alpha for this scale is $82 \%$.

\section{RESULTS}

The samples that participated in the present study consisted of female (22.4 percent) and male (77.6 percent). The respondents' age range varies from 21 to 58 years old, and the respondents' age average out at 40.21 years. 18.3 percent of the respondents were high school diploma or less than that, where as 67.1 percent of them hold bachelor degrees and only 14.7 percent hold master degree and above. The organization position of the sample was further drawn into the 10.6 percent managers, 63.4 percent professionals and 26 percent clerical personnel. 
Table 1 Correlation matrix for Six Bureaucratic Dimensions

\begin{tabular}{|c|c|c|c|c|c|c|c|c|}
\hline Dimension & Mean & $\begin{array}{c}\text { Std. } \\
\text { Deviation }\end{array}$ & HA & RO & JC & FRM & DL & TC \\
\hline HA & 3.64 & 0.81 & 1 & & & & & \\
\hline RO & 3.38 & 0.51 & $0.42^{* *}$ & 1 & & & & \\
\hline JC & 3.52 & 0.72 & $0.09^{*}-$ & 0.02 & 1 & & & \\
\hline FRM & 3.02 & 0.66 & $0.24^{* *}$ & $0.15^{* *}$ & $0.16^{* *}-$ & 1 & & \\
\hline DL & 2.89 & 0.66 & 0.03 & $0.09^{*}$ & $0.16^{* *}-$ & 0.05 & 1 & \\
\hline TC & 2.52 & 0.87 & $0.29-^{* *}$ & $0.22^{* *}-$ & $0.37^{* *}$ & $0.30^{* *}-$ & $0.21^{* *}-$ & 1 \\
\hline
\end{tabular}

$*<0.05$

$* *<0.01$

Table 1 shows the mean, standard deviation and Correlation matrix between the bureaucratic dimensions of organizational structure. As it's obvious, bureaucratic dimensions change independently and we can't consider them as a unitary concept. There are positive relations among hierarchy of authority, rules observation, formality of the relations and division of labor. But on the other hand, these variables have negative relations with technical competence and job codification. Also the relation between job codification and technical competence is a positive and significant relation. Generally according to the table, we can say that in this case, there are two sets of variables that are inversely correlated together. Dimensions of technical competence and job codification have negative relations with the dimensions including hierarchy of authority, job codification, rules observation, formality of the relationships and division of labor. Among these dimensions, perceptions of employees of hierarchy of authority in the organization has the highest level (mean=3.64). And perceptions of employees of technical competence in the organization has the lowest level (mean $=2.52$ ). All the correlation coefficients among the dimensions are significant, except correlation between rules observation and job codification, division of labor and hierarchy of authority, and division of labor and formality of relationships .

By reviewing table 1, we could conclude the following points:

1) When hierarchy of authority is stronger in an organization, rules observation will increase. 2) Stronger hierarchy of power in an organization will increase the formality of relationships in the organization. 3) When hierarchy of power is stronger, job codification becomes weaker. 4) When hierarchy of power is stronger, technical competence is less. 5) When rules observation is stronger, formality of the relations in an organization will increase. 6) When rules observation is stronger, division of labor will increase. 7) When rules observation is stronger, technical competence will decrease. 8) When job codification is more detailed, formality of relationships will decrease. 9) When job codification is more detailed, division of labor will be less. 10) When job codification is more detailed, technical competence will increase. 11) When the formality of relationships in an organization increase, technical competence will decrease. 12) When division of labor increases, technical competence will decrease. Also the results show that the strongest correlations exist between hierarchy of authority and rules observation, and between technical competence and job codification. 
Table 2 Factor Analysis of Six Bureaucratic Dimensions.

-1:Total Variance Explained Table 2

$\mathrm{Kmo}=0.614$

bartlett's test $=249.431$

$\operatorname{sig}=0.000$

\begin{tabular}{|c|c|c|c|c|c|c|c|c|c|}
\hline \multirow{2}{*}{$\begin{array}{l}\vec{\Xi} \\
\stackrel{\Xi}{0} \\
\stackrel{0}{\Xi} \\
0\end{array}$} & \multicolumn{3}{|c|}{ Initial Eigenvalues } & \multicolumn{3}{|c|}{$\begin{array}{l}\text { Extraction sums of squared } \\
\text { loadings }\end{array}$} & \multicolumn{3}{|c|}{ sums of squared loadings Rotation } \\
\hline & Total & $\begin{array}{c}\text { \% of } \\
\text { Variance }\end{array}$ & $\begin{array}{c}\text { Cumulative } \\
\%\end{array}$ & Total & $\begin{array}{c}\% \text { of } \\
\text { Variance }\end{array}$ & $\begin{array}{c}\text { Cumulative } \\
\%\end{array}$ & Total & $\begin{array}{c}\text { \% of } \\
\text { Variance }\end{array}$ & $\begin{array}{c}\text { Cumulative } \\
\%\end{array}$ \\
\hline 1 & 1.982 & 33.029 & 33.029 & 1.982 & 33.029 & 33.029 & 1.685 & 28.082 & 28.082 \\
\hline 2 & 1.260 & 20.998 & 54.027 & 1.260 & 20.998 & 54.027 & 1.557 & 25.945 & 54.027 \\
\hline 3 & .946 & 15.761 & 69.787 & & & & & & \\
\hline 4 & .765 & 12.751 & 82.538 & & & & & & \\
\hline 5 & .536 & 8.926 & 91.464 & & & & & & \\
\hline 6 & .512 & 8.536 & 100.000 & & & & & & \\
\hline & & \multicolumn{8}{|c|}{ Table 2-2:Rotated Component Matrix(Varimax) } \\
\hline & & & & & \multicolumn{5}{|c|}{ Component } \\
\hline & & & & & \multicolumn{2}{|r|}{1} & & \multicolumn{2}{|c|}{2} \\
\hline & & & HA & & \multicolumn{2}{|c|}{.828} & & \multicolumn{2}{|c|}{-.011} \\
\hline & & & TC & & \multicolumn{2}{|c|}{-.432} & & \multicolumn{2}{|c|}{.669} \\
\hline & & & DL & & \multicolumn{2}{|c|}{$.066-$} & & \multicolumn{2}{|c|}{-.592} \\
\hline & & & RO & & \multicolumn{2}{|c|}{.776} & & \multicolumn{2}{|c|}{.069} \\
\hline & & \multicolumn{3}{|c|}{ JC } & \multicolumn{2}{|r|}{.010} & & \multicolumn{2}{|c|}{.783} \\
\hline & & \multicolumn{2}{|r|}{ FRM } & & \multicolumn{2}{|r|}{.451} & & \multicolumn{2}{|c|}{-.377} \\
\hline
\end{tabular}

Table 2 shows the results of the factor analysis of six bureaucratic dimensions. In table 1-2 we can see the total explained variance, initial eigenvalues, eigenvalue of extracted factors with and without rotation. As you can see, the 1 and 2 factors that have greater eigenvalues than one remain in the analysis. The remaining factors explain about the $52 \%$ of the total variance. After rotation of factors, the first factor explains about $28 \%$ and the second factor explains about $26 \%$ of the variance. According to table 2-2 we can find out that 6 bureaucratic dimensions form two high-order factors. The first factor includes hierarchy of authority, rules observation and formality. This factor is called control. The second factor includes job codification, technical competence and division of labor. This factor is called expertise. As you can see, contrary to job codification and technical competence, division of labor has negative loading on the expertise. It can be said that although division of labor loades highly on the expertise, but it is at the opposite end of the factor continum when it is compared to two dimensions job codification and technical competence. Also table 3 shows Pierson's correlation between two high-order factors, expertise and control. As you can see, since the $r=-0.24$ and sig=0.000, there's a significant and negetive relationship between expertise and control. That is, the higher the degree of control in the organization, the lower the degree of expertise in the organization .

Table 3: Pearson's correlation coefficient between expertise and control

\begin{tabular}{|c|c|c|}
\hline Sig & $r$ & \\
\hline 0.000 & -0.24 & $\begin{array}{c}\text { expertise and } \\
\text { control }\end{array}$ \\
\hline
\end{tabular}

Table 4 shows a quick cluster analysis of the scores of employees on two factors, control and expertise, results in 4 specific groups of employees. For this, we have used K-mean cluster analysis. The K-mean cluster analysis is a method used when a theory exists about number of clusters. By this method we can provide means for each cluster on control and expertise. The first cluster is called Weberian. There are 84 employees in this cluster. Control mean in this cluster is 3.64 which is higher than the overall mean of control for all employees (3.34); and 
expertise mean in this cluster is 3.30 which is higher than the overall mean of expertise for all employees (2.99). The second cluster is called collegial. There are 102 employees in this cluster. The control mean in this cluster is (2.87) which is lower than overall mean of control for all employees (3.34); and the expertise mean in this cluster is 3.33 which is higher than overall mean of expertise for all employees (2.99). The third cluster is called authoritarian. There are 61 employees in this cluster. Control mean in this cluster is 4.01 which is higher than overall mean of control for all employees (3.34); and expertise mean in this cluster is 2.54 which is lower than overall mean of expertise for all employees (2.99). The fourth cluster is called chaotic. There are 112 employees in this cluster. Control mean in this cluster is 3.22 which is lower than overall mean of control for all employees. Expertise mean in this cluster is (2.67) which is lower than overall mean of expertise for all employees (2.99). A great number of employees are in this cluster. This means that perception of the most employees of bureaucracy of administrative organizations is chaotic bureaucracy.

To assess the significant difference among these four groups of employees on control and expertise factors, we have used ANOVA. Hence, two ANOVA's have been undertaken. In the first one, we have considered control as the dependent variable and in the second one, expertise has been considered as the dependent variable. And in both of them, four clusters have been used as independent variables. As evident in table 5, both ANOVA's have been confirmed with a level of confidence lower than 0.99. It means that there are significant differences between four clusters on control factor. The mean of control was highest for employees in the authoritarian cluster followed by weberian, chaotic and collegial clusters. Also there were significant differences between four groups on expertise factor. The mean of expertise was highest for employees in the collegial cluster followed by weberian, chaotic and authoritarian clusters in this order. It must be noted, although most of the employees of this study is grouped in the chaotic category of bureaucracy, but the level of control and expertise in these organizations is not very low and it's less likely that the employees feel that there's anarchy in the organization. Because the control mean in the chaotic group is higher than control mean in the collegial group. Also the expertise mean in the chaotic group is higher than the expertise mean in the authoritarian group.

Table 4 Quick Clusters of Cases Based on Two factors.

\begin{tabular}{|c|c|c|c|c|c|}
\hline \multirow[t]{2}{*}{ factors } & \multicolumn{4}{|c|}{ Final cluster centers } & Total \\
\hline & $\begin{array}{c}\text { Weberian } 1 \\
\mathrm{~N}=84\end{array}$ & $\begin{array}{c}\text { Collegial } 2 \\
N=102\end{array}$ & $\begin{array}{c}\text { 3Authoritarian } \\
\mathrm{N}=61\end{array}$ & $\begin{array}{l}\text { 4Chaotic } \\
\mathrm{N}=112\end{array}$ & $\mathrm{~N}=359$ \\
\hline CONTROL & $\begin{array}{l}3.64 \\
\text { High }\end{array}$ & $\begin{array}{l}2.87 \\
\text { Low }\end{array}$ & $\begin{array}{l}4.01 \\
\text { High }\end{array}$ & $\begin{array}{l}3.22 \\
\text { Low }\end{array}$ & 3.34 \\
\hline EXPERTISE & $\begin{array}{l}3.30 \\
\text { High }\end{array}$ & $\begin{array}{l}3.33 \\
\text { High }\end{array}$ & $\begin{array}{l}2.54 \\
\text { Low }\end{array}$ & $\begin{array}{l}2.67 \\
\text { Low }\end{array}$ & 2.99 \\
\hline
\end{tabular}

Table 5 ANOVAs for Control and Expertise factors by Clusters.

\begin{tabular}{|c|c|c|c|c|c|c|c|c|}
\hline $\begin{array}{c}\text { Dependent } \\
\text { variable }\end{array}$ & Mean & SD & Source & $\begin{array}{c}\text { Sum of } \\
\text { Squares }\end{array}$ & df & $\begin{array}{l}\text { Mean } \\
\text { Square }\end{array}$ & $\mathbf{F}$ & Sig \\
\hline \multirow{3}{*}{ CONTROL } & \multirow{3}{*}{3.34} & \multirow{3}{*}{0.47} & $\begin{array}{l}\text { Between } \\
\text { Groups }\end{array}$ & 59.13 & 3 & 19.71 & 307.08 & 0.000 \\
\hline & & & $\begin{array}{l}\text { Within } \\
\text { Groups }\end{array}$ & 22.78 & 355 & .064 & & \\
\hline & & & Total & 81.91 & 358 & & & \\
\hline \multirow{3}{*}{ EXPERTISE } & \multirow{3}{*}{2.99} & \multirow{3}{*}{0.42} & $\begin{array}{l}\text { Between } \\
\text { Groups }\end{array}$ & 43.16 & 3 & 14.38 & 232.08 & 0.000 \\
\hline & & & $\begin{array}{l}\text { Within } \\
\text { Groups }\end{array}$ & 21.95 & 355 & .062 & & \\
\hline & & & Total & 65.11 & 358 & & & \\
\hline
\end{tabular}




\section{CONCLUSION}

This research was undertaken to study bureaucratic dimensions of structure of Iran's administrative organizations, as a developing country. Results of the internal relations among bureaucratic dimensions of Iran's administrative organizations showed that in the administrative organizations of this country, bureaucracy is multidimensional and we couldn't consider it as a unitary concept. Iranian employees reported a high level of hierarchical authority in the organization. Also they perceive that promotion in these organizations is not based on technical competence. The results of correlations matrix of bureaucratic dimensions showed that the dimensions of technical competence and job codification are reversely related to hierarchy of authority, rules observation, formality and division of labor. According to the results of correlations matrix, it seems that there are two sets of variables which are reversely related to each other. Findings of the factor analysis showed that 6 dimensions of the bureaucratic structure form two high-order factors. First factor is control including Hierarchy of authority, rule observation and formality in relations. Second factor is expertise including job codification, technical competence and division of labor. Both factors are reversely related to each other. This means that when control increase in the organization, expertise decrease. As you could see, findings of the present study are to some extents different from the results of western studies. Western studies claimed that two dimensions of division of labor and technical competence make the expertise factor which is reversely related to the control factor that includes 4 dimensions of hierarchy of authority, formality, rules observation and job codification. Also in the present study 6 dimensions of the bureaucratic structure make two high-order factors, control and expertise which are reversely related, with this difference that, in the present study, the expertise factor includes three dimensions of technical competence, division of labor and job codification. The control factor includes three dimensions of hierarchy of power, rules observation and formality. Because the most variance of job codification variable has not been explained by control factor, but by expertise factor. There was no negative relation between job codification and technical competence, but their relation was significant, positive and strong. On the other hand, the relation of job codification with hierarchy of authority, impersonality and division of labor is negative. Of the other differences of this study's findings, we can mention the division of labor variable. Similar to the findings of Anderson 1973, Eisherwood \& Hoy, 1973,Yucel, 1999 and also in the present study the division of labor was loaded on the expertise factor, but in the present sample, its relationship with expertise is negative. This means that the stronger the division of labor is, the expertise will decrease. Also there's a reversed relation between division of labor and job codification and technical competence, which have a positive relationship with expertise factor. This means that the more the division of labor in the organization is, job codification and technical competence will decrease. Hence, contrary to the findings of studies by Anderson, 1973; Eisherwood\&Hoy, 1973; Yucel, 1999, the more the activities of the organization are organized on functional specialization, the fewer employees would regard technical competence and expertise, as required by promotion. It seems that the reason for this is partially due to differences in forms of specialization in different organizations. It could be said that the specialization that in line with technical competence, leaves a positive impact on expertise factor, is more a social professionalism -division of labor based on expertise and skill of individuals- rather than a functional specialization. By functional specialization, employees accomplish few numbers of professional tasks and the type of work is specific, simple and repetitive. When the tasks are divided on functional specialization, it means using human resources to do specific, simple and repetitive responsibilities. Employees, especially those professional ones who have attended professional training courses, will not much be able to use their skills and expertise in their tasks. While in social specialization, tasks are organized on the expertise of individuals, and they are assigned with a broad range of authorities to accomplish their related tasks (Hall, 1999). Since lack of balance between expertise of 
employees and the tasks assigned to them, is one of the common problems in the administrative organizations of the developing countries, it seems that in the present sample, tasks have been organized mostly on functional specialization.

About job codification, it suggests that the reason for its difference can also be due to different job codifications in several organizations. Job codification can be viewed as "coercive" when rules limit workers 's rights to exert significant control over their work activities. On the other hand, job codification can be viewed as "enabling" when it provides needed guidance and clarifies job responsibilities, thereby reducing role ambiguity(Sarros et al, 2002). In the present sample, it seems the job responsibilities are ambiguous and not detailed. Thus not only job codifications are as coercive, but it's assumed that in order to accomplish their tasks professionally, employees are in need for detailed information and clear codifications of their responsibilities and activities. Kanango $(1992,1981)$ believes that in the organizations of the developing countries, job codifications have not been clarified for the employees. Therefore, a problem called "ambiguity in jobs and responsibilities" emerge. In this situation, due to lack of efficiency of information sharing system, and weakness of the organization in regulation of job codifications, employees don't have a clear recognition of their job, its objectives and their professional responsibilities. Also the difference between job codification and rules observation in this case, shows that although the job codifications have not been fully clarified for the employees, they are monitored to abide by these ambiguous rules.

According to the positive relations between hierarchy of authority and rules observation, and the negative relations between hierarchy of authority and job codification, it can be suggested that one of the reason why employees face ambiguity in rules and job standards, is that they don't have a role in enacting these rules and job standards, or can't influence them. This is while on the other hand, they are monitored to abide by these ambiguous rules. As korman points out (1991) when those who define norms and criteria are originally outsiders, that's when problems occur, because norms and criteria mostly mirror the ideas of the one who has defined them. On the other hand, the positive relation between job codification and promotion based on technical competence shows that the more clear and detailed criteria and norms are, the more the promotions will be done based on technical competence. This reveals that when rules and criteria are clear and detailed, organization will be more successful in presenting a clear image of criteria for remuneration and promotion to the employees. And employees will have a clearer understanding of how they'll be promoted based on technical competence. But as Kanango (1992) states, most of the organizations of developing countries suffer from lack of a suitable and efficient evaluation system . In these organizations, there is no justice as well as the evaluation system and its criteria are ambiguous.

Also in this study, employees have been categorized in four clusters (Authoritarian, Weberian, Collegial and Chaotic) on Control and Expertise factors. In this sample, a larger number of employees were in the chaotic cluster. In the chaotic cluster, employees experience low degrees of control and low degrees of expertise in the organization. As mentioned before, in chaotic bureaucracies, ambiguity and contradiction are evident. The dominant source of authority is political connections. Decisions are made in an irrational way and there's no coordination of activities. Such organizations are unstable. Although it must be mentioned that it's less likely that the employees of these organizations feel that there's anarchy in the organization, because the level of control and expertise in these organizations is not very low. These results are also similar to the results of Yucel's study (1999) on bureaucratic structurs of schools in Turkey. 
Nevertheless we must mention that: the internal relations among bureaucratic dimensions in Iran's governmental organizations are rather different than the results of western studies. However there's a need for more studies in non-western countries and cultures, because such studies in non-western and developing countries are few. Studing these relations in different countries and cultures and comparing them to each other will reveal the more differences between western and non-western bureaucratic structurs. And since the model of bureaucratic organizations were originally developed based on western studies in western countries, assessment and comparison of organizational structures in different countries and cultures will undoubtedly add to our general knowledge about organizations.

\section{Reference}

Aiken, M. \& Hage, J. (1966) "Organization alienation : a comparative analysis", American Sociological Review, vol.31 (August) : 497-507.

Anderson, B. D.(1971)Reactions to a study of bureaucracy and alienation, Social Forces49(June): 614-621.

Anderson, B. D.(1973) School bureaucratization and alienation from high shool, Sociology of Education, Vol. 46(Summer): 315-334.

Berger, M. (1956-57) Bureaucracy east and west. Administrative Science Quarterly; 1, 518-529.

Blau, P. M. \& Scott, W. R. (1962). Formal organizations: a comparative approach. San Francisco: Chandler.

Blau, P. ; Marshal, M. (1974). Bureaucracy in modern society, Translated by N. Farzanamnia, Tehran, Pishbord Publication. (Persian)

Bonjean, ch. M. ; Grimes, M. D.(1970), Bureaucracy And alienation :A dimensional Approach, Social Forces 48 (march) : 365-373.

Bonjean, ch. M. ; Grimes, M. D.(1971), Some issues in the study of bureaucracy and alienation, social forces 49 (June) : 622-630.

Gerth, H. and Mills, C. W. (1946). From Max Weber: Essays in sociology. New York: Oxford University Press.

Giddenz, A. (2003). sociology. $4^{\text {th }}$ ed, polity press.

Hage, J. , Aiken, M. (1967)The relationship of centralization to other structure properties, Administrative Science Quarterly,12: 72-92.

Hall,R. H.(1962), Intraorganizational stractural variation: Application of the Bureaucratic Model, Administrative Science Quarterly 7, No.3: 259-308.

Hall, R. H. (1963). The concept of bureaucracy: An empirical assessment. American Journal of Sociology; 69 (1), 32-40.

Hall, R. H. Tittle, C. R.(1966). A note on bureaucracy and its correlates. American Journal of Sociology72(November): 267-272.

Hall, R. H. (1968). Professionalization and bureaucratization. Administrative Science Quarterly;3(1), 92-104.

Hall, R. H. (1997). Organization, Translated by A. Parsian and M. Darabi, Tehran, cultural researchs press. (Persian)

Isherwood, G. B. and Hoy, W.(1973). Bureaucracy powerlessness and teacher work values. Journal of Educational Administration;11, 124-138.

Kanungo,R. N. (1992). Management in developing countries, Machmilan Press.

Kanungo ,R. N. (1981). Work alienation and involment problems and prospects, International Review of Applied Psychology, Vol.30, No.1.

Korman, A. (2005) Industrial and Organizational Psychology, Translated by H.Shokrkon, Tehran, Roshd Publication, $4^{\text {th }}$ press . (Persian)

Krejcie, R. \& Morgan, D. (1970) ."Determining sample size for research activities”, Educational and Psychological Measurement 30: 607-610.

Meyers, R. W. (1972). School system bureaucratization and teachers' sense of power. Paper presented at the annual meeting of the American Association. Chicago III., April 1972. 
Moeller, G. H. \& Charters, W. W. (1966). Relation of bureaucratization to sense of power among teachers. Administrative Science Quarterly; 11(1), 444-465.

Punch, K. F. (1969). Bureaucratic structure in schools: toward redefinition and measurement. Educational Administration Quarterly; 5, 43-57.

Robinson,S. (1997). Organization theory, Translated by S.M. Alvani and H. Danaifard, Tehran, Saffar Publication. (Persian)

Sarros, J.c ; Tanewski, G.A. ; Winter, R.p ; Santora , J.C. ; Densten , I.l. (2002) "Work alienation and organizational leadership", British Journal of Management, 13 (4): 285-304.

Udy, S. Jr. (1959). Bureaucracy and rationality in Weber's organizational theory: an empirical study. Administrative Science Quarterly;24(6), 791-795.

Yucel ,cemil (1999). Bureacracy and teachers'sense of power , Doctoral dissertation . Blacksburg , Virginia university . 